\title{
Engagement with a Web-Based Health Promotion Intervention among Vocational School Students: A Secondary User and Usage Analysis
}

\author{
Gerrit Stassen ${ }^{1, *}$, Christopher Grieben ${ }^{2}$, Ingo Froböse ${ }^{2}$ and Andrea Schaller ${ }^{1}$ \\ 1 Working Group Physical Activity-Related Prevention Research, Institute of Movement Therapy \\ and Movement-oriented Prevention and Rehabilitation, German Sport University Cologne, \\ D-50933 Cologne, Germany; a.schaller@dshs-koeln.de \\ 2 Department 1: Movement-oriented Prevention and Rehabilitation Sciences, Institute of Movement \\ Therapy and Movement-oriented Prevention and Rehabilitation, German Sport University Cologne, \\ D-50933 Cologne, Germany; c.grieben@dshs-koeln.de (C.G.); froboese@dshs-koeln.de (I.F.) \\ * Correspondence: g.stassen@dshs-koeln.de
}

Received: 5 February 2020; Accepted: 17 March 2020; Published: 25 March 2020

\begin{abstract}
Engagement with web-based interventions is both generally low and typically declining. Visits and revisits remain a challenge. Based on log data of a web-based cluster randomized controlled trial conducted in vocational schools, the present secondary analysis aimed to identify influencing factors on initially logging in to a health promotion platform among young adults and to examine the engagement over the course of an eight-week intervention. Data of 336 students (62.2\% female, age span 18-25) from two intervention arms (web-based intervention and web-based intervention with an additional initial face-to-face contact) was included. Binary logistic regression and log-data visualization were performed. An additional initial face-to-face contact (odds ratio $(\mathrm{OR})=2.971$, $p=0.005)$, female sex $(\mathrm{OR}=2.237, p=0.046)$ and the health-related skill "dealing with health information" (OR = 2.179, $p=0.030)$ significantly increased the likelihood of initially logging in. Other variables showed no influence. $16.6 \%$ of all potential users logged in at least once, of which $57.4 \%$ revisited the platform. Most logins were tracked at the beginning of the intervention and repeated engagement was low. To increase the engagement with web-based interventions, health-related skills should be fostered. In addition, a strategy could be to interlink comparable interventions in vocational schools more regularly with everyday teaching through multi-component interventions.
\end{abstract}

Keywords: web-based platform; vocational school students; initial face-to-face contact; engagement; logistic regression; log-data visualization

\section{Introduction}

As today's leading medium, the internet offers great potential and wide reach for health promotion [1,2]. Especially among younger target groups, it is already established as a primary source of health information [3-5].

Nevertheless, engagement with web-based interventions for health promotion is generally low and high attrition rates are typical [6-8]. At the beginning of an intervention, three key stages are usually important: that users access the website (or a comparable web-based program), stay there, and revisit it [9].

The combination of digital and analogue study components, e.g., through an initial kick-off or mixed intervention designs, can increase engagement with web-based interventions $[10,11]$. Other intervention components that have been shown to have a positive impact on engagement include tailored prompts or reminders and regular updates [12-15]. 
However, it can be observed that actual users are often not necessarily those who should be using a web-based health program [16,17], which reconfirms the inverse care law [18]. A higher level of engagement with in web-based health programs is again associated with, e.g.,: female sex, normal weight, compliance with guidelines for healthy behavior, and higher health literacy [17,19-22].

A more difficult target group to reach is young adults, especially young men, who use the internet more often in general and more often as a source of health information, but who often show low levels of use and revisits to web-based interventions $[7,17,21,23]$. In addition, young adults are an often-overlooked target group in health promotion [24,25], although they have high societal relevance as a future workforce [26,27] in increasingly aging Western societies [28]. At the same time, the phase of "emerging adulthood" (age span 18-25 years) is essential for personality development and the exploration of possibilities [29] and has a major impact on the manifestation of healthy behaviors and well-being [30-33]. A promising strategy for addressing young target groups through web-based interventions is integration into social contexts, e.g., in educational institutions [13].

Against the background of the great potential of web-based health promotion, but also low and decreasing participation, user and usage analyses for the identification of (non) user characteristics as well as engagement patterns are of increasing importance [34-36].

Based on a web-based intervention cluster randomized controlled trial conducted in vocational schools [37,38], the following research questions were investigated: (1) What are influencing factors among vocational school students on initially logging in to a web-based health promotion platform? (2) What is the overall engagement and the engagement like during the course of an intervention in a web-based intervention group compared to a group with an additional initial face-to-face contact?

\section{Materials and Methods}

\subsection{Study Design and Participants}

The present study involved secondary analyses of the main phase of the WebApp study [37], which was conducted as a three-armed cluster randomized controlled trial with three measuring points (T0-baseline (start of the intervention), T1—end of eight-week intervention, T2-six-month follow-up) starting in February/March 2017 (Figure 1). WebApp dealt with the health literacy promotion of vocational school students. Three forms (33 classes in total) from three different schools from three different urban districts in Cologne, North Rhine-Westphalia, Germany, were recruited based on project-related cooperation agreements with the German Sports University Cologne and randomly assigned to the following study conditions: web-based intervention (WEB), web-based intervention with an additional initial face-to-face contact $(W E B+F T F)$, or control (CON, no access to the web-based platform). All participants were completing commercial vocational training (typically lasting 3 years) and were in their first year of training, except for one class.

During the study, all classes continued to participate in regular lessons of the school subject sports/health promotion which-according to the curriculum of the federal state of North Rhine-Westphalia [39] -is compulsory across all training programs and aims to contribute to personality development and to support a self-determined health-promoting way of living. Participation in the study was voluntary and did not interfere with regular schooling for the duration of the study.

In the evaluation of the WebApp main phase [38], neither WEB nor WEB + FTF was more effective in terms of health literacy promotion compared with CON. None of the study conditions showed a significant improvement in health literacy.

As in the evaluation of the study's main phase [38], the present user and usage analyses included only students aged 18-25 years following Arnett's conception of "emerging adulthood" [29]. Data of underaged and students outside the age span was not included. The corresponding baseline sample (33 classes, $n=565, n=495$ in the age span 18-25 years) was reduced to the two intervention groups and the intervention period (Figure 1), resulting in a final sample of $n=336$ (23 classes, WEB: 149, $W E B+F T F: 187$ ) (Figure 2). Written informed consent was obtained from all participants in the 
sample. The Ethics Committee of the German Sport University Cologne has approved the study (reference: 118/2015).

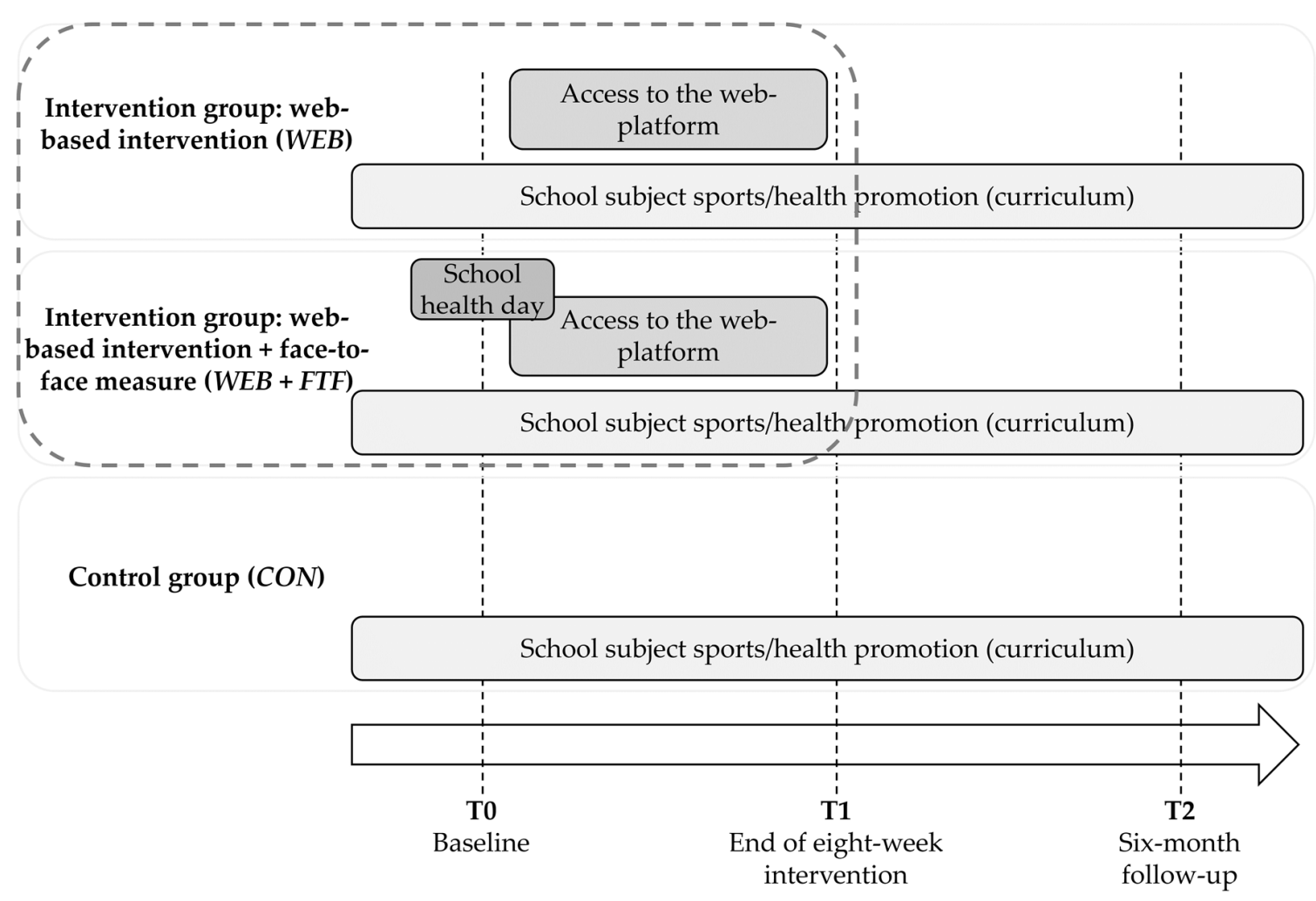

Figure 1. Study design (cluster randomized controlled trial, encircled: study segments of the secondary analysis).

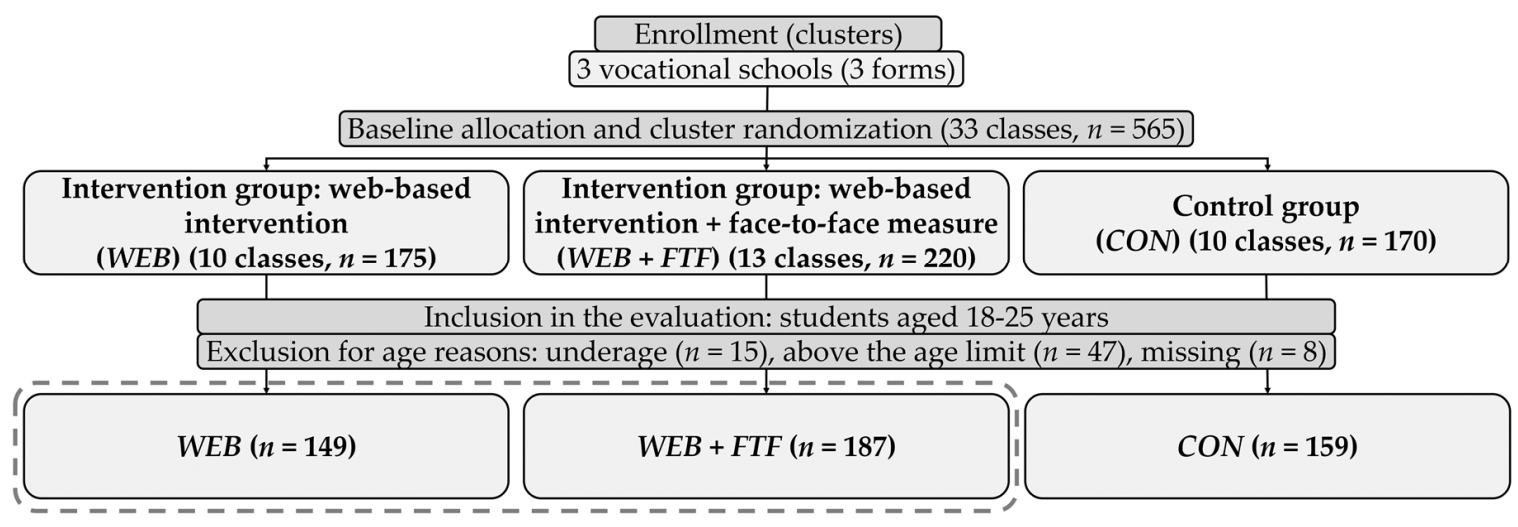

Figure 2. Analysis inclusion flow chart (encircled: study conditions of the secondary analysis).

\subsection{Intervention Groups}

\subsubsection{Web-Based Intervention (WEB)}

The main objective of the web-based intervention was to strengthen competencies regarding a healthy lifestyle. For the realization of the web-based platform, an e-learning software (Talentsoft $\mathrm{GmbH}$, Cologne, Germany) was used. The software provided responsive design. The web-based platform was developed based on focus groups with vocational school students, which were conducted in an earlier project stage (results presented elsewhere [40]). 
Interactive functions were integrated (profile function, private messages, newsfeed). On the homepage the timeline, updates, and personal progress were displayed and different sections of the platform were accessible via the header, including the learning modules (Figure 3).

The content section included modules covering seven specific topics: general information (main focus: physical activity), clarification of misinformation, healthy nutrition, quick recipes, motivation, check-ups, and quizzes. The content section was updated about once a week, seven times during the eight-week intervention. The content was designed to be interactive, using various multimedia formats and was tailored to the target group in terms of language, scope and complexity.

Structure and content were identical for both groups, but the two platforms were independent of each other. After the baseline measurements, the participants of both intervention groups received invitation emails with individual accounts. During the intervention, all users received short email reminders describing the updated contents about once a week.

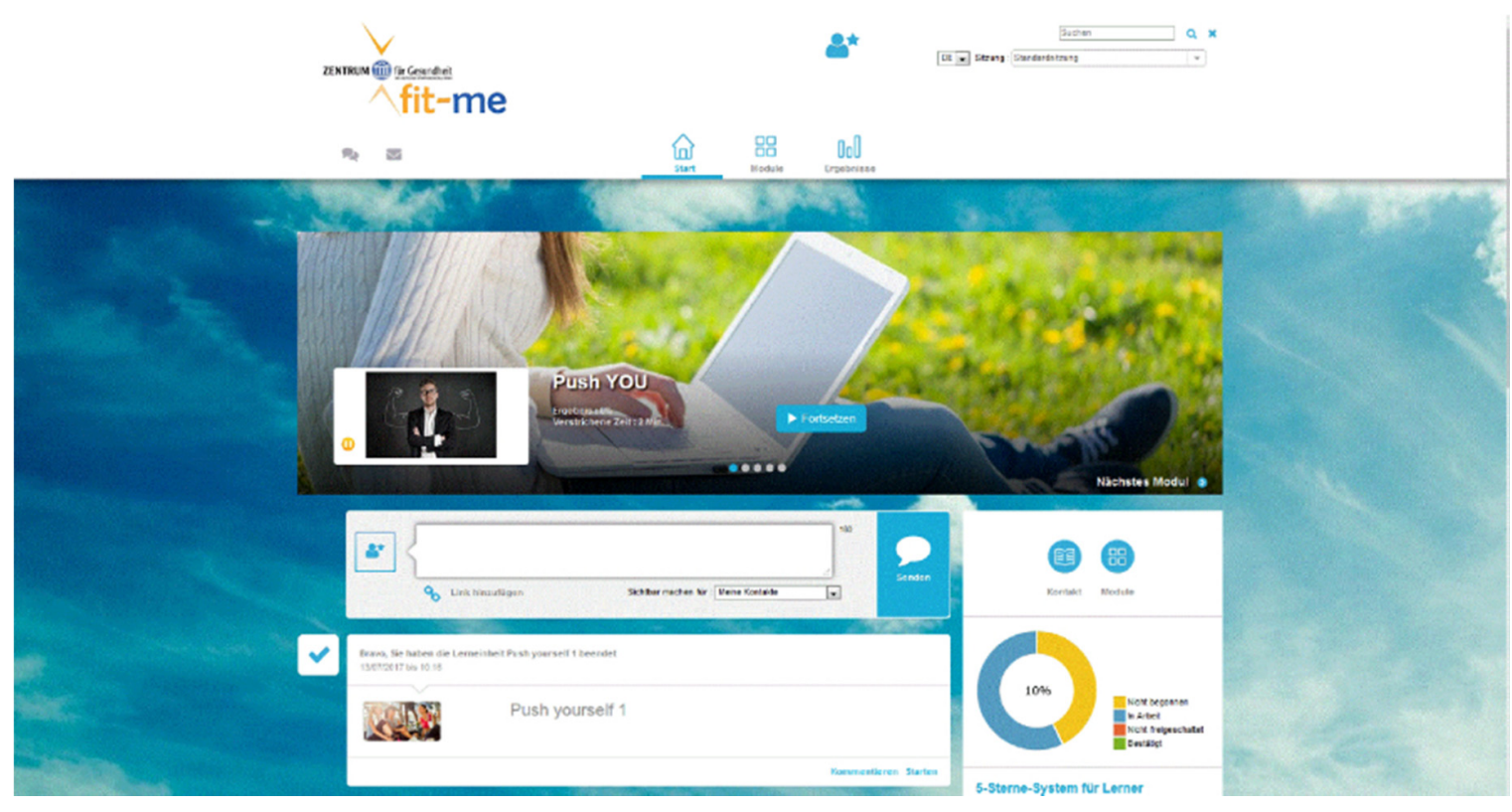

Figure 3. Homepage of the web-based platform.

\subsubsection{Web-Based Intervention with an Initial Face-to-Face Contact $(W E B+F T F)$}

In addition to platform access $(W E B)$, a school health day was conducted during a regular school day (obligatory participation) before the start of the intervention $(W E B+F T F)$. The topics were occupational health management, brief relaxation at the workplace and stress management, healthy nutrition, fitness tests, health check-ups, and the presentation of the platform. The aim was to sensitize the students to health topics and to present the platform through personal contact.

\section{3. $\log$-Data}

Log-data was automatically tracked by the e-learning software and could be extracted by the authors via an admin function. The software tracked the user ID and the login time. Every listed login during the intervention period was included in the analyses.

\subsection{Measures}

All measurements (paper-pencil questionnaires) took place during regular school lessons or the school health day, respectively, and were voluntary.

Sex, height and weight for body mass index (BMI) calculation were based upon self-report. 
For measuring work ability, the German short version of the Work Ability Index was used (WAI) [41]. The WAI results in a score from 7-49 which-following the (re)classifications of Kujala and colleagues for young employees [42]—allows a classification into four categories: poor work ability (score 7-36), moderate (37-40), good (41-44), excellent (45-49). The questionnaire relates well with objective measurements [43,44], has an acceptable test-retest reliability [45], and prognostic value regarding sickness absence [46].

Subjective psychological well-being was assessed with the German version of the 5-item World Health Organization Well-Being Index (WHO-5) [47]. The sum score ranges from 0-25 and is multiplied by 4 . A score of $\leq 50$ indicates a reduced well-being [48]. The questionnaire has been shown to have a high clinimetric validity and is established as tool for comparing well-being between groups $[48,49]$.

Physical activity was measured using a German translation of the one single question by Milton and colleagues ("In the past week, on how many days have you done a total of 30 minutes or more of physical activity, which was enough to raise your breathing rate.") [50]. This single-item assessment tool has a strong test-retest reliability $(r=0.86)$ and modest validity $(r=0.53)$ against the Global Physical Activity Questionnaire in an adult population (18-64 years) [50]. It enables assessment of whether respondents meet the recommendations of at least five days of 30 minutes of physical activity per week [51].

Health literacy was measured using Lenartz's German questionnaire on health literacy. The questionnaire depicts the structural model of health literacy developed by Lenartz, Soellner and colleagues [52,53] and comprises 29 items representing the six "advanced skills" of the model: "self-perception", "proactive approach to health", "dealing with health information", "self-control", "self-regulation", and "communication and cooperation". The possible answers are "not correct at all", "rather not correct", "rather correct", and "correct" (scale 1-4). The values are calculated by averaging [52]. The questionnaire proved to be reliable (Cronbach's $\alpha$ for the six "advanced skills" $=0.70-0.89$ ) [53] and the model was cross-validated with different samples [52-54].

\subsection{Statistical Analyses and Visualizations}

A binary logistic regression was used to answer research question (1). Initially logging in to the web-based platform was used as the dependent variable (at least one login vs. no login). Intervention group (WEB + FTF vs. WEB), sex (female vs. male), BMI ( $<25$ normal weight vs. $\geq 25$ overweight), well-being (score $>50$ vs. $\leq 50$ ), work ability (excellent/good vs. moderate/poor), physical activity ( $\geq 5$ days of 30 minutes per week vs. $<5$ days), and the six "advanced skills" of the structural model of health literacy were included as independent variables. The dichotomizations were based on established cut-off values (see 2.4. Measures) to analyze the influence of various risk factors. Cases with missing values were excluded from the analysis.

Independent samples t-tests or Mann-Whitney U-tests, respectively, and chi-square were used to examine research question (2) regarding the proportion of users, the proportion of revisitors, and the login frequency. Furthermore, for each time point of the web-based intervention, i.e., for the time after the invitation e-mail and after subsequent updates, the relative proportion of users within the two study conditions (students with at least one login divided by the size of the respective intervention group) was calculated. A scatter diagram was created for both intervention groups, with the users of both interventions groups on the y-axis and the time points of the web-based intervention on the $\mathrm{x}$-axis, to visualize at which time points each user logged in at least once, with the lines in between indicating repeated engagement over multiple time points.

The significance level was set at $p<0.05$ for all tests. The data was analyzed using IBM SPSS Statistics 26 (IBM Corp., Armonk, NY, USA).

\section{Results}

Of the sample (Table 1$)$, the majority $(62.2 \%)$ were female and mean age was $20.6 \pm 1.9$ years. $56.0 \%$ had a reduced well-being, $52.2 \%$ showed "poor"/"moderate" work ability, and $71.3 \%$ did not 
meet the physical activity recommendations. Scores of the six "advanced skills" of the structural model of health literacy varied between 2.6-3.0.

Table 1. Baseline values $(n=336)$.

\begin{tabular}{cc}
\hline Characteristic, Outcome & $\boldsymbol{n}$ (\%) $\mathbf{1} / \mathbf{M e a n} \pm$ SD \\
\hline Sex (female) & $209(62.2)$ \\
Age (years) & $20.6 \pm 1.9$ \\
BMI & $23.8 \pm 4.7$ \\
Overweight (BMI $\geq 25)^{2}$ & $101(30.7)$ \\
WAI score (range 7-49) & $39.6 \pm 4.6$ \\
Poor/moderate work ability (score $\leq 40)^{3}$ & $168(52.2)$ \\
WHO-5 score (range 0-100) & $47.5 \pm 17.5$ \\
Reduced well-being (score $\leq 50)^{4}$ & $187(56.0)$ \\
Days/week $\geq 30$ minutes of physical activity & $3.2 \pm 2.0$ \\
Not meeting recommendations (<5 days/week) ${ }^{5}$ & $239(71.3)$ \\
Structural model of health literacy: "advanced skills" (scale 1-4) & \\
Self-perception & $3.0 \pm 0.4$ \\
Proactive approach to health & $2.6 \pm 0.6$ \\
Dealing with health information & $2.8 \pm 0.6$ \\
Self-control & $2.9 \pm 0.5$ \\
Self-regulation & $2.6 \pm 0.6$ \\
Communication and cooperation & $2.6 \pm 0.6$ \\
\hline
\end{tabular}

Note: ${ }^{1}$ Valid percentages due to missing data. SD—standard deviation. BMI—body mass index. WAI—Work Ability Index. WHO-5-World Health Organization Well-Being Index. ${ }^{2}$ [55]. ${ }^{3}$ [42]. ${ }^{4}$ [48]. ${ }^{5}$ [51].

\subsection{Influencing Factors on Intially Logging in}

The logistic regression showed that the model as a whole $\left(\chi^{2}(12)=21.625, p=0.042\right)$ was significant (Table 2). Intervention group and female sex increased the likelihood of initially logging in by 2.971 and 2.237 times, respectively, and if "dealing with health information" increased by one unit, the likelihood of initially logging in increased 2.179 times. Other variables showed no influence.

Table 2. Logistic regression model with initially logging in ${ }^{1}$ as dependent variable $(n=289)$.

\begin{tabular}{cccccc}
\hline Factor & B & SE & $p$ & OR & 95\%-CI \\
\hline Intervention group (WEB + FTF vs. WEB) & 1.089 & 0.384 & $0.005^{* *}$ & 2.971 & $1.399 ; 6.309$ \\
Sex (female vs. male) & 0.805 & 0.404 & $0.046^{*}$ & 2.237 & $1.014 ; 4.934$ \\
BMI (<25 vs. $\geq 25$ ) & -0.254 & 0.387 & 0.512 & 0.776 & $0.398 ; 1.788$ \\
Work Ability (WAI score $>$ 40 vs. $\leq 40)$ & -0.170 & 0.383 & 0.657 & 0.844 & $0.398 ; 1.788$ \\
Well-being (WHO-5 score > 50 vs. $\leq 50)$ & 0.120 & 0.404 & 0.767 & 1.127 & $0.511 ; 2.487$ \\
Physical activity ( $\geq 5$ days vs. $<5)$ & -0.215 & 0.403 & 0.593 & 0.806 & $0.366 ; 1.775$ \\
Self-perception & 0.056 & 0.431 & 0.896 & 1.058 & $0.455 ; 2.462$ \\
Proactive approach to health & -0.017 & 0.318 & 0.957 & 0.983 & $0.527 ; 1.833$ \\
Dealing with health information & 0.799 & 0.358 & $0.030 *$ & 2.179 & $1.081 ; 4.393$ \\
Self-control & 0.079 & 0.390 & 0.840 & 1.082 & $0.504 ; 2.324$ \\
Self-regulation & -0.213 & 0.339 & 0.530 & 0.808 & $0.415 ; 1.572$ \\
Communication and cooperation & 0.071 & 0.306 & 0.816 & 1.074 & $0.589 ; 1.958$ \\
\hline
\end{tabular}

Note: ${ }^{1}$ Dependent variable: at least one login vs. no login. B—unstandardized regression coefficient, SE—standard error, OR—odds ratio, CI—confidence interval. BMI—body mass index. WAI—Work Ability Index. WHO-5—World Health Organization Well-Being Index. $p<0.05^{*} . p<0.01^{* *}$. Nagelkerke's $R^{2}=0.123$.

\subsection{Engagement}

Of all potential users, $16.1 \%(54 / 336)$ logged in at least once, and $57.4 \%$ of those revisited the platform. In WEB, 9.4\% (14/149) logged in at least once, whereas in WEB + FTF $21.4 \%(40 / 187)$ logged in, which means a significantly higher proportion of users $\left(\chi^{2}(1)=8.845, p=0.003\right.$ ) (Table 3). In terms 
of proportion of revisitors, the groups did not differ. The login frequency did not differ, despite a tendency towards WEB. In total, 146 logins were tracked (WEB: 45, WEB + FTF: 101).

Table 3. Overall use of the web-based platform.

\begin{tabular}{|c|c|c|c|}
\hline Measure & $\begin{array}{c}\text { WEB } \\
\mathrm{n}(\%)^{1 / \text { Mean } \pm \text { SD }}\end{array}$ & $\begin{array}{c}\text { WEB + FTF } \\
\text { n }(\%)^{1} / \text { Mean } \pm \text { SD }\end{array}$ & $p$ \\
\hline Proportion of users ${ }^{2}$ & $14(9.4)$ & $40(21.4)$ & $0.003^{* *}$ \\
\hline Proportion of revisitors ${ }^{3}$ & $9(64.3)$ & $22(55.0)$ & 0.545 \\
\hline Login frequency ${ }^{3}$ & $3.2 \pm 2.3$ & $2.5 \pm 4.1$ & 0.124 \\
\hline
\end{tabular}

Figure 4 shows the course of participation based on the relative proportion of users (students with at least one login divided by the size of the respective intervention group). The highest participation was from WEB + FTF after the invitation emails (16.6\%). Apart from this, the relative proportion of users within the two intervention groups was always below $5 \%$ for each subsequent time point of the web-based intervention, i.e., after the subsequent updates. In both groups, the majority of the total number of logins within the group were tracked after the invitation email and before the first update (WEB: $35.6 \%$, WEB + FTF: 59.4\%).

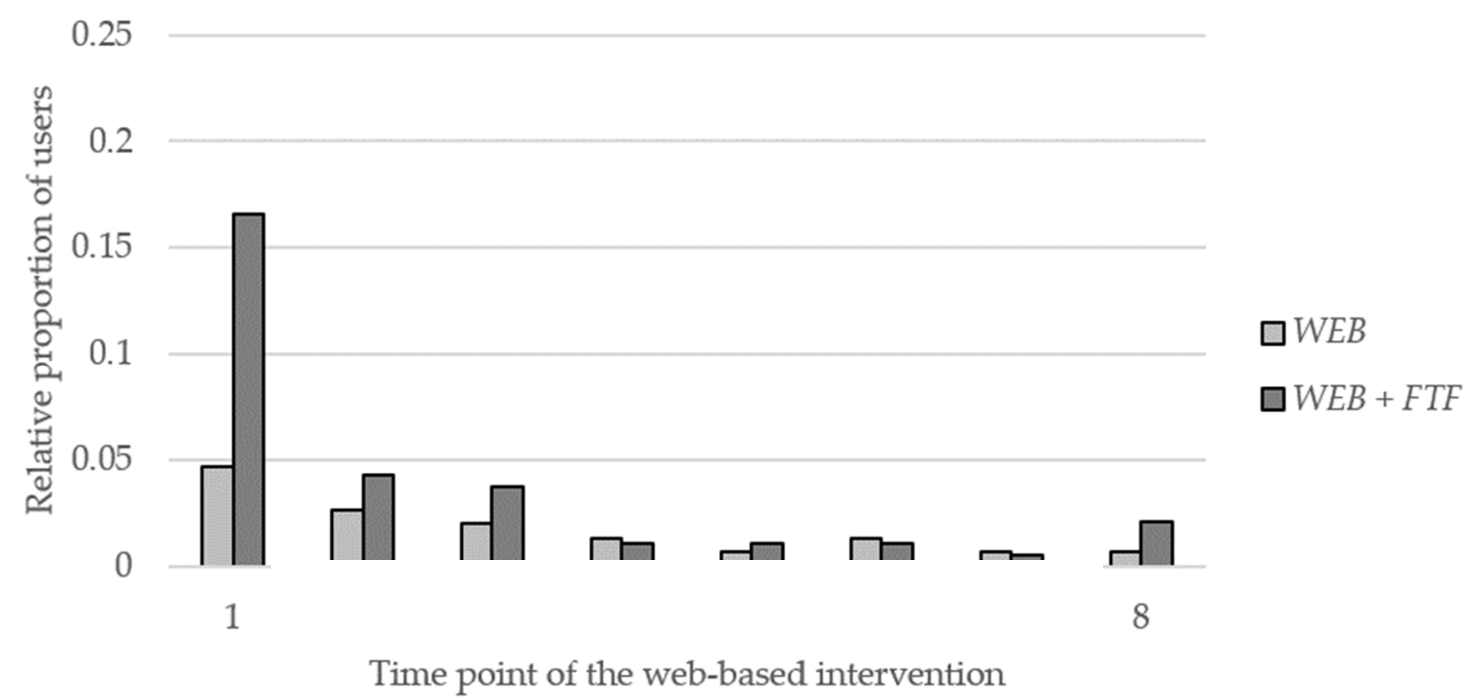

Figure 4. Relative proportion of users during the web-based intervention (time point: 1 -after invitation emails; 2-8-after subsequent update).

The scatter diagram (Figure 5) visualizes at which time points of the web-based intervention each user logged in at least once (squares: $W E B$, dots: $W E B+F T F$, lines in between indicating repeated engagement). For eight users $(14.8 \%)$, repeated engagement could be observed between at least two time points of the web-based intervention. One user in WEB+FTF logged in after both the invitation email and all seven updates. 


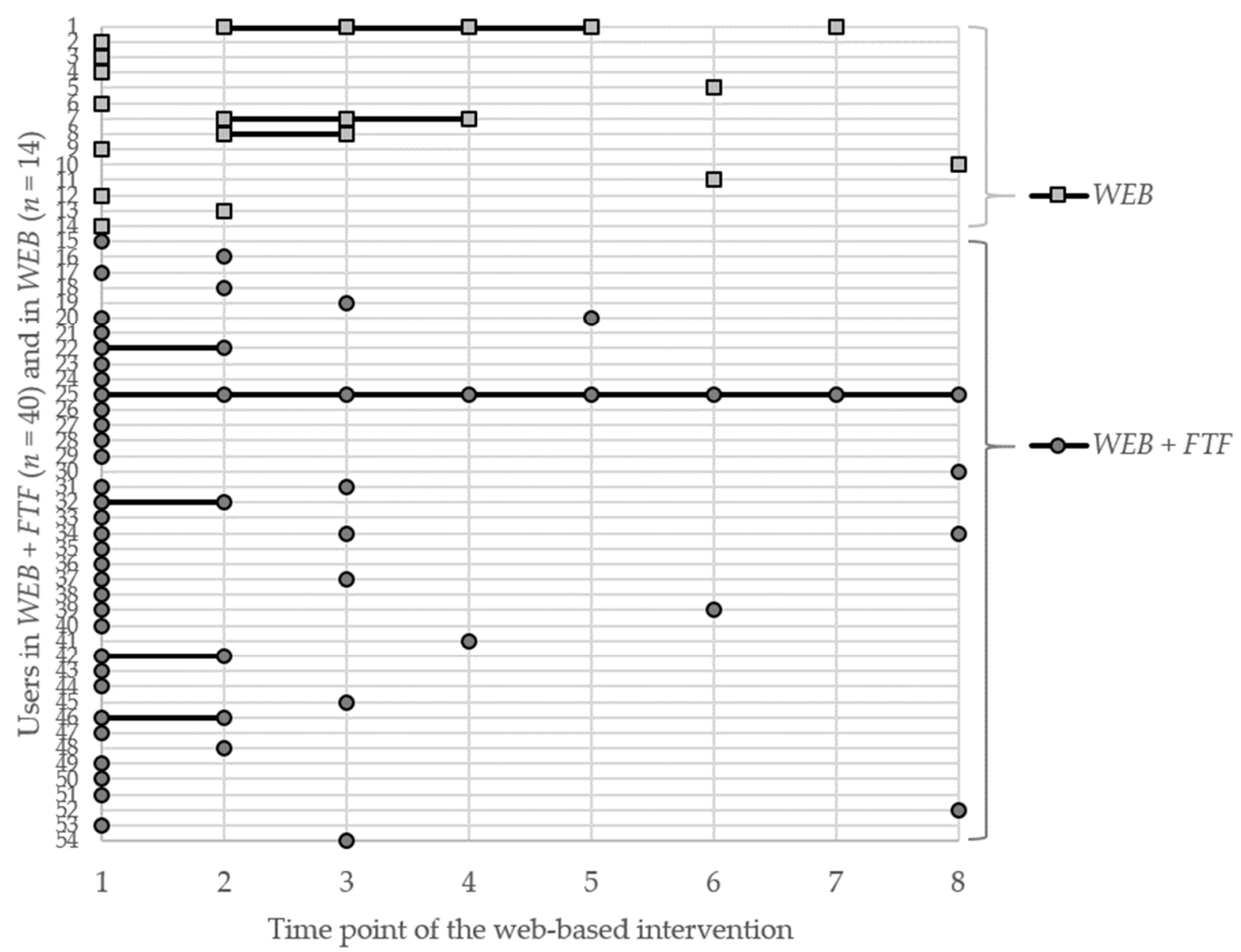

Figure 5. Scatter diagram visualizing the time points of the web-based intervention at which each user logged in at least once (time point: 1-after invitation emails; 2-8-after subsequent update).

\section{Discussion}

Engagement with the web-based intervention was low, both in terms of the proportion of users and revisitors and in the further course of the study. An additional initial face-to-face contact, female sex, and a higher score in "dealing with health information" significantly increased the likelihood of initially logging in to the web-based intervention platform.

With regard to the baseline values for overweight [56], work ability [42], well-being [57], meeting physical activity recommendations [58], and health literacy [52], it can be stated that they are comparable to German surveys or corresponding studies with young adults, which makes the study population to a certain extent representative of the target group of vocational school students. The higher number of female participants is influenced by commercial vocational training, which is more popular among women [59]. The generalizability of the results is limited with regard to other age groups or settings. However, since a majority of web-based health promotion studies targeting young adults are conducted in university settings $[25,60,61]$, the present study has a great added value with regard to non-academic settings.

In web-based health promotion in general, it has already been proven that potential male users are more difficult to reach and show higher dropout rates and less use of online health information $[7,21,23,62]$. Moreover, young men are considered a partially neglected target group in health promotion in general [63-65]. Specific surveys of this subgroup show that a combination of personal and web-based appointments could be promising [66].

Regarding the structural model of health literacy, only "dealing with health information" - the ability to understand and integrate health-related information into one's personal life-had an impact on initially logging in to the web-based platform. Actively managing one's health is associated with use of the internet for information about healthcare and healthy lifestyle information [67]. In addition, low 
health literacy is negatively associated with the evaluation of online health information [68]. On the other hand, due to the non-impact of the other "advanced skills" of the structural model, this result should be viewed with caution, as students with a higher levels of health literacy may not have seen the need to use a (further) source of information. The use of online resources for health information specifically requires eHealth literacy skills, which should be trained in young adults [69]. Further research is needed to explore in detail the relationship between health literacy and the use of target group-oriented web-based health information.

The fact that increased BMI, reduced well-being, reduced work ability, and insufficient physical activity and all other skills of the health literacy model did not influence initially logging may underline that those who use a (digital) health promotion measure are not always the people who should be doing so. Therefore, it remains challenging to reach risk subgroups within heterogeneous target groups, which is why special attention should be paid to less responsive groups, both in the planning and implementation of studies [21,70].

Regarding the implementation, the analyses show that an additional initial face-to-face contact can positively influence the absolute proportion of users who log on to a web-based platform. However, in both intervention groups the majority of logins were tracked in the time between the invitation emails and the first update; in WEB + FTF even more than half, so that no further sustainable effect can be deduced in the present study with regard to engagement. The purposeful and also repetitive and continued integration of face-to-face components at multiple time points of a web-based intervention, e.g., as a blended intervention, can lead to an increase in adherence [14]. Blending online and offline learning content within a curriculum is considered more valuable than online learning alone [71]. Studies show that in educational institutions the possibility of using a web-based health program during teaching time and not only during leisure time is a crucial factor for regular usage [72,73]. The integration of web-based measures into everyday school life can reduce barriers to use, e.g., low motivation [74].

Accordingly, it must be considered that at least one further face-to-face meeting, e.g., in the middle of the study, might have been beneficial. As stand-alone web-based interventions appear to be less effective than multi-component interventions [75], there may be increased potential when combined with more regular face-to-face contact.

In a larger context, however, research has shown that web-based measures without initial face-to-face contact have a comparable effectiveness to those without, especially when the initial appointment is usually only a technical instruction [76]. This has important implications for the dissemination of interventions, since although participation following face-to-face contacts may be higher in comparison, the overall reach increases significantly without [76]. Accordingly, digital and face-to-face measures should only be combined if the combination has added value in terms of the intervention objective.

Since in both groups the majority of logins and the highest relative proportion of users were tracked in the first week of the intervention, following which usage decreased, it becomes clear that reminders and updates could not attenuate attrition in the present study. The low number of users for whom repeated engagement could be observed confirms this. Research suggests that periodic reminders and tailored prompts to use (web-based) health interventions can have a positive impact on engagement [77-79], especially if they are additionally combined with personal contact [80]; neither of these components was used in the present study. The optimal frequency still needs to be investigated [77,81], because a high frequency can also lead to "fatigue" and thus to ignoring [7]. Studies also show that website updates have positive effects on the proportion of revisitors $[12,14,65]$, but probably not if the first visit to a platform was not engaging.

Furthermore, different interests and needs of specific subgroups should be considered and specifically addressed. Otherwise, the intervention approach might not be appropriate for any group in retrospect, since a "one-size-fits-all" approach is unlikely to satisfy the preferences of the various users [82]. Future interventions for young user groups should be app-oriented due to current usage 
behavior and should include personalized and tailored feedback and content, self-monitoring and goal-setting, and social interaction and comparison [82-84]. Similar components were also mentioned in the focus groups in an earlier project phase of the WebApp study [40], but could not be fully realized in the main phase of the study due to technical reasons and lack of IT resources. Participation processes can quickly accumulate broad ideas, but these may no longer be within the scope of what is feasible. A clear, reduced framework and appropriate objectives should therefore already be set before an intervention is developed.

When planning web-based measures for young adults, the special phase of life of this target group should always be carefully considered. Young adults, including vocational school students, are in a life phase characterized by exploration and self-orientation [29], especially at the beginning of a training course or study. Factors such as pleasure, appearance and well-being are much more important for this very specific target group than prevention and health promotion $[85,86]$. To prevent inappropriate addressing and wrong framing of health information [85-87], very target group-specific web-based strategies are necessary.

Despite previous target group participation, the final platform might have been too information-heavy and not low-threshold enough. Even though the content was designed to be interactive and tailored to the target group, the platform approach was most likely unsuitable for the current usage and information behavior of the target group. Potential users must be able to recognize a personal benefit and, in the best case, be well entertained to some extent in order to engage with prevention and health.

All in all, the low user rates underline the challenge of target group-oriented web-based prevention measures for young adults. The low login frequency does not indicate stable use, and, looking at the course of the study, users lost interest after a short time. The generally well-known phenomenon of high dropout rates in web-based interventions was confirmed. In future interventions, attention should be paid to the crucial moments in terms of engagement, namely the hurdle of the first visit, the challenge of ensuring that users stay with an offer and that they return [9]. Interdisciplinarity is more important than ever to design modern digital interventions and to keep pace with technological and societal developments [88-90]. Nonetheless, insights into measures with a rather low engagement levels continue to be very valuable in driving forward the development of future measures $[8,91]$.

\section{Limitations}

First, the selected usage parameter, i.e., logins, gives a broad insight into usage frequency but not into deeper engagement $[92,93]$. Usage or engagement can be distinguished between extent of usage as behavior, i.e., amount or frequency, and subjective experience, e.g., attention and interest [35]. The scientific discussion on the operationalization of engagement and the selection of use metrics is ongoing $[35,94,95]$. Since we have taken logins as a meaningful measure for our secondary post-hoc usage analysis [96] to get a general overview of the participation, we cannot draw any conclusions about individual experience. Against the background of the known high drop-out rates, in-depth analyses of the perception and usability of web-based measures for potential users are necessary. The Technology Acceptance Model [97] or the System Usability Scale [73] offer possible approaches. Also, no intended engagement use was predefined [98,99], as the intervention was not designed with a strict modular structure, e.g., in the sense of a teaching series.

Secondly, regarding the factors that influence initially logging in, the regression analysis did not integrate further variables that are known to influencing engagement, such as intention and motivation for behavior change $[34,79,100]$, perceiving personal relevance [101], or social class and education level [102]. Future studies should consider these aspects in young adults. In addition, both the WAI and the WHO-5 are established instruments, but the use of the one single question to measure physical activity can in turn be viewed critically. Only a few instruments for measuring physical activity show sufficient reliability and validity [103,104]. Furthermore, the selected and internationally barely established health competence questionnaire makes comparisons with other 
studies difficult. The questionnaire remains to be translated and further validated. Nevertheless, it offers an insight into individual skills within a health literacy model and starting points for future studies. The operationalization of health literacy and the choice of a measurement instrument remains a subject of current discussions $[105,106]$.

Thirdly, engagement over the course of the study was only examined descriptively. Due to the open intervention format, which means that the updates did not build on each other, further statistical analyses of the course of logins were not carried out. Instead, log-data visualization was used to get an impression of the course as an alternative way of investigating engagement $[107,108]$. In strictly modular or sequenced interventions, survival analysis methods, e.g., Kaplan-Meier analysis, allow for adherence and attrition analyses [8].

\section{Conclusions}

Young adults are a heterogeneous target group and find themselves in a special phase of life, which is why a "one-size-fits-all" intervention approach does not seem very promising. Therefore, especially risk subgroups, such as young men, should be addressed more specifically.

Since prevention and health promotion play a subordinate role among vocational school students and young adults in general, a pronounced interest in health topics or a high level of intention to use (web-based) health promotion measures cannot necessarily be assumed. To increase the engagement with web-based interventions, however, health-related skills, such as the ability to understand and integrate health-related information into one's personal life, should be fostered.

With regard to implementation, it can be stated that an initial face-to-face contact can have a positive influence on the absolute proportion of users, but does not necessarily lead to a long-term stable engagement, even if reminders and updates are used. A possible strategy could be to interlink future web-based interventions in vocational schools more regularly with everyday teaching by means of multi-component interventions, so that the advantages of both sides (more frequent face-to-face contact and a contemporary approach) can complement each other.

Author Contributions: Conceptualization, G.S., C.G., I.F. and A.S.; methodology, G.S., C.G. and A.S.; validation, G.S. and A.S.; formal analysis, G.S. and A.S.; investigation, G.S. and C.G.; resources, I.F. and A.S.; data curation, G.S. and C.G.; writing—original draft preparation, G.S.; writing—review and editing, G.S., C.G., I.F. and A.S.; visualization, G.S.; supervision, C.G. and A.S.; project administration, G.S. and C.G.; funding acquisition, C.G., I.F. and A.S. All authors have read and agreed to the published version of the manuscript.

Funding: This research was funded by the Federal Ministry of Education and Research (BMBF), grant number 01EL1425A. The WebApp study is a subproject within the research association TRISEARCH.

Acknowledgments: We want to thank Laura Goretzka and Markus Möckel for their support during the project implementation and the data collection and Jasmin Podlech for her preparatory works. Additionally, the authors want to express their gratitude to all study participants and to the cooperation schools and their teachers for the support during the planning and execution of the data collection.

Conflicts of Interest: The authors declare no conflicts of interest.

\section{References}

1. Muñoz, R.F. Using evidence-based internet interventions to reduce health disparities worldwide. J. Med. Internet Res. 2010, 12, e60. [CrossRef]

2. Vandelanotte, C.; Müller, A.M.; Short, C.E.; Hingle, M.; Nathan, N.; Williams, S.L.; Lopez, M.L.; Parekh, S.; Maher, C.A. Past, Present, and Future of eHealth and mHealth Research to Improve Physical Activity and Dietary Behaviors. J. Nutr. Educ. Behav. 2016, 48, 219-228. [CrossRef] [PubMed]

3. van de Belt, T.H.; Engelen, L.J.L.P.G.; Berben, S.A.A.; Teerenstra, S.; Samsom, M.; Schoonhoven, L. Internet and social media for health-related information and communication in health care: Preferences of the Dutch general population. J. Med. Internet Res. 2013, 15, e220. [CrossRef] [PubMed]

4. Beck, F.; Richard, J.-B.; Nguyen-Thanh, V.; Montagni, I.; Parizot, I.; Renahy, E. Use of the internet as a health information resource among French young adults: Results from a nationally representative survey. J. Med. Internet Res. 2014, 16, e128. [CrossRef] [PubMed] 
5. Montagni, I.; Cariou, T.; Feuillet, T.; Langlois, E.; Tzourio, C. Exploring Digital Health Use and Opinions of University Students: Field Survey Study. JMIR Mhealth Uhealth 2018, 6, e65. [CrossRef] [PubMed]

6. Wangberg, S.C.; Bergmo, T.S.; Johnsen, J.-A.K. Adherence in Internet-based interventions. Patient Prefer. Adherence 2008, 2, 57-65.

7. Geraghty, A.W.A.; Torres, L.D.; Leykin, Y.; Pérez-Stable, E.J.; Muñoz, R.F. Understanding attrition from international Internet health interventions: A step towards global eHealth. Health Promot. Int. 2013, 28, 442-452. [CrossRef]

8. Eysenbach, G. The law of attrition. J. Med. Internet Res. 2005, 7, e11. [CrossRef]

9. Crutzen, R.M.M. Hard to Get, Hard to Keep: Dissemination of and Exposure to Internet-delivered Health Behaviour Change Interventions Aimed at Adolescents. Ph.D. Thesis, University of Maastricht, Maastricht, The Netherlands, 2009.

10. Lau, P.W.C.; Lau, E.Y.; Wong, D.P.; Ransdell, L. A systematic review of information and communication technology-based interventions for promoting physical activity behavior change in children and adolescents. J. Med. Internet Res. 2011, 13, e48. [CrossRef]

11. Lentferink, A.J.; Oldenhuis, H.K.; de Groot, M.; Polstra, L.; Velthuijsen, H.; van Gemert-Pijnen, J.E. Key Components in eHealth Interventions Combining Self-Tracking and Persuasive eCoaching to Promote a Healthier Lifestyle: A Scoping Review. J. Med. Internet Res. 2017, 19, e277. [CrossRef]

12. Brouwer, W.; Kroeze, W.; Crutzen, R.; de Nooijer, J.; de Vries, N.K.; Brug, J.; Oenema, A. Which intervention characteristics are related to more exposure to internet-delivered healthy lifestyle promotion interventions? A systematic review. J. Med. Internet Res. 2011, 13, e2. [CrossRef] [PubMed]

13. Crutzen, R.; de Nooijer, J.; Brouwer, W.; Oenema, A.; Brug, J.; de Vries, N.K. Strategies to facilitate exposure to internet-delivered health behavior change interventions aimed at adolescents or young adults: A systematic review. Health Educ. Behav. 2011, 38, 49-62. [CrossRef] [PubMed]

14. Kelders, S.M.; Kok, R.N.; Ossebaard, H.C.; van Gemert-Pijnen, J.E.W.C. Persuasive system design does matter: A systematic review of adherence to web-based interventions. J. Med. Internet Res. 2012, 14, e152. [CrossRef] [PubMed]

15. Kelders, S.M.; van Gemert-Pijnen, J.E.W.C.; Werkman, A.; Nijland, N.; Seydel, E.R. Effectiveness of a Web-based intervention aimed at healthy dietary and physical activity behavior: A randomized controlled trial about users and usage. J. Med. Internet Res. 2011, 13, e32. [CrossRef]

16. Kelders, S.M.; van Gemert-Pijnen, J.E.W.C.; Werkman, A.; Seydel, E.R. Usage and effect of a web-based intervention for the prevention of overweight; a RCT. Stud. Health Technol. Inform. 2010, 160, $28-32$.

17. Verheijden, M.W.; Jans, M.P.; Hildebrandt, V.H.; Hopman-Rock, M. Rates and determinants of repeated participation in a web-based behavior change program for healthy body weight and healthy lifestyle. J. Med. Internet. Res. 2007, 9, e1. [CrossRef]

18. Jameson, J.E. Inverse care law. Lancet 1971, 297, 648-649. [CrossRef]

19. Brouwer, W.; Oenema, A.; Raat, H.; Crutzen, R.; de Nooijer, J.; de Vries, N.K.; Brug, J. Characteristics of visitors and revisitors to an Internet-delivered computer-tailored lifestyle intervention implemented for use by the general public. Health Educ. Res. 2010, 25, 585-595. [CrossRef]

20. Robroek, S.J.W.; Brouwer, W.; Lindeboom, D.; Oenema, A.; Burdorf, A. Demographic, behavioral, and psychosocial correlates of using the website component of a worksite physical activity and healthy nutrition promotion program: A longitudinal study. J. Med. Internet Res. 2010, 12, e44. [CrossRef]

21. van der Mispel, C.; Poppe, L.; Crombez, G.; Verloigne, M.; de Bourdeaudhuij, I. A Self-Regulation-Based eHealth Intervention to Promote a Healthy Lifestyle: Investigating User and Website Characteristics Related to Attrition. J. Med. Internet Res. 2017, 19, e241. [CrossRef]

22. Mackert, M.; Mabry-Flynn, A.; Champlin, S.; Donovan, E.E.; Pounders, K. Health Literacy and Health Information Technology Adoption: The Potential for a New Digital Divide. J. Med. Internet Res. 2016, 18, e264. [CrossRef] [PubMed]

23. Reinwand, D.A.; Schulz, D.N.; Crutzen, R.; Kremers, S.P.; de Vries, H. Who Follows eHealth Interventions as Recommended? A Study of Participants' Personal Characteristics From the Experimental Arm of a Randomized Controlled Trial. J. Med. Internet Res. 2015, 17, e115. [CrossRef] [PubMed]

24. National Academy of Sciences; Committee on Improving the Health, Safety and Well-Being of Young Adults; Bonnie, R.J.; Stroud, C.; Breiner, H. Investing in the Health and Well-Being of Young Adults; The National Academies Press: Washington, DC, USA, 2015. 
25. Oosterveen, E.; Tzelepis, F.; Ashton, L.; Hutchesson, M.J. A systematic review of eHealth behavioral interventions targeting smoking, nutrition, alcohol, physical activity and/or obesity for young adults. Prev. Med. 2017, 99, 197-206. [CrossRef] [PubMed]

26. Sumanen, H.; Pietiläinen, O.; Lahti, J.; Lahelma, E.; Rahkonen, O. Sickness absence among young employees: Trends from 2002 to 2013. J. Occup. Health 2015, 57, 474-481. [CrossRef]

27. Boström, M.; Holmgren, K.; Sluiter, J.K.; Hagberg, M.; Grimby-Ekman, A. Experiences of work ability in young workers: An exploratory interview study. Int. Arch. Occup. Environ. Health 2016, 89, 629-640. [CrossRef]

28. United Nations. World Population Ageing 2017-Highlights; Department of Economic and Social Affairs, Population Division: New York, NY, USA, 2017.

29. Arnett, J.J. Emerging adulthood: A theory of development from the late teens through the twenties. Am. Psychol. 2000, 55, 469-480. [CrossRef]

30. Due, P.; Krølner, R.; Rasmussen, M.; Andersen, A.; Trab Damsgaard, M.; Graham, H.; Holstein, B.E. Pathways and mechanisms in adolescence contribute to adult health inequalities. Scand. J. Public Health 2011, 39 (Suppl. 6), 62-78. [CrossRef]

31. Daw, J.; Margolis, R.; Wright, L. Emerging Adulthood, Emergent Health Lifestyles: Sociodemographic Determinants of Trajectories of Smoking, Binge Drinking, Obesity, and Sedentary Behavior. J. Health Soc. Behav. 2017, 58, 181-197. [CrossRef]

32. Lawrence, E.M.; Mollborn, S.; Hummer, R.A. Health lifestyles across the transition to adulthood: Implications for health. Soc. Sci. Med. 2017, 193, 23-32. [CrossRef]

33. Arnett, J.J.; Žukauskienè, R.; Sugimura, K. The new life stage of emerging adulthood at ages 18-29 years: Implications for mental health. Lancet Psychiatry 2014, 1, 569-576. [CrossRef]

34. van 't Riet, J.; Crutzen, R.; de Vries, H. Investigating predictors of visiting, using, and revisiting an online health-communication program: A longitudinal study. J. Med. Internet Res. 2010, 12, e37. [CrossRef] [PubMed]

35. Perski, O.; Blandford, A.; West, R.; Michie, S. Conceptualising engagement with digital behaviour change interventions: A systematic review using principles from critical interpretive synthesis. Transl. Behav. Med. 2017, 7, 254-267. [CrossRef] [PubMed]

36. Crutzen, R.; Cyr, D.; de Vries, N.K. Bringing loyalty to e-Health: Theory validation using three internet-delivered interventions. J. Med. Internet Res. 2011, 13, e73. [CrossRef] [PubMed]

37. Grieben, C.; Stassen, G.; Froböse, I. Internetbasierte Gesundheitsförderung. Prävention und Gesundh. 2017, 12, 154-159. [CrossRef]

38. Stassen, G.; Grieben, C.; Sauzet, O.; Froböse, I.; Schaller, A. Health literacy promotion among young adults: A web-based intervention in German vocational schools. Health Educ. Res. 2020, 35, 87-98. [CrossRef] [PubMed]

39. Schulsport NRW. Lehrplan zur Erprobung Sport/Gesundheitsförderung in den Fachklassen der dualen Berufsausbildung. Available online: https://www.schulsport-nrw.de/fileadmin/user_upload/ schulsportpraxis_und_fortbildung/pdf/sport_gesundheitsfoerderung.pdf (accessed on 21 February 2020).

40. Grieben, C.; Stassen, G.; Froböse, I. How Should Web-Based Physical Activity and Healthy Eating Interventions be Designed for Young Office Workers? A Qualitative Approach. J. Healthc. Commun. 2018, 3. [CrossRef]

41. Hasselhorn, H.M.; Freude, G. Der Work Ability Index Ein Leitfaden; Wirtschaftsverl. NW Verl. für neue Wiss: Bremerhaven, Free Hanseatic City of Bremen, Germany, 2007.

42. Kujala, V.; Remes, J.; Ek, E.; Tammelin, T.; Laitinen, J. Classification of Work Ability Index among young employees. Occup. Med. (Lond.) 2005, 55, 399-401. [CrossRef]

43. Eskelinen, L.; Kohvakka, A.; Merisalo, T.; Hurri, H.; Wägar, G. Relationship between the self-assessment and clinical assessment of health status and work ability. Scand. J. Work Environ. Health 1991, 17 (Suppl. 1), $40-47$.

44. Nygård, C.H.; Eskelinen, L.; Suvanto, S.; Tuomi, K.; Ilmarinen, J. Associations between functional capacity and work ability among elderly municipal employees. Scand. J. Work Environ. Health 1991, 17 (Suppl. 1), 122-127.

45. de Zwart, B.C.H.; Frings-Dresen, M.H.W.; van Duivenbooden, J.C. Test-retest reliability of the Work Ability Index questionnaire. Occup. Med. (Lond.) 2002, 52, 177-181. [CrossRef]

46. Notenbomer, A.; Groothoff, J.W.; van Rhenen, W.; Roelen, C.A.M. Associations of work ability with frequent and long-term sickness absence. Occup. Med. (Lond.) 2015, 65, 373-379. [CrossRef] [PubMed] 
47. WHO Collaborating Center for Mental Health. WHO (Fünf)_Fragebogen zum Wohlbefinden: (Version 1998); Frederiksborg General Hospital, Frederiksberg: Copenhagen, Denmark, 1998; Available online: https://www.psykiatri-regionh.dk/who-5/Documents/WHO5_German.pdf (accessed on 28 November 2019).

48. Topp, C.W.; Østergaard, S.D.; Søndergaard, S.; Bech, P. The WHO-5 Well-Being Index: A systematic review of the literature. Psychother. Psychosom. 2015, 84, 167-176. [CrossRef] [PubMed]

49. Hall, T.; Krahn, G.L.; Horner-Johnson, W.; Lamb, G. Examining functional content in widely used Health-Related Quality of Life scales. Rehabil. Psychol. 2011, 56, 94-99. [CrossRef]

50. Milton, K.; Bull, F.C.; Bauman, A. Reliability and validity testing of a single-item physical activity measure. Br. J. Sports Med. 2011, 45, 203-208. [CrossRef] [PubMed]

51. Stanner, S. At Least Five a Week-A summary of the report from the Chief Medical Officer on physical activity. Nutr. Bull. 2004, 29, 350-352. [CrossRef]

52. Lenartz, N. Gesundheitskompetenz und Selbstregulation; V\&R unipress: Göttingen, Lower Saxony, Germany, 2012.

53. Soellner, R.; Lenartz, N.; Rudinger, G. Concept mapping as an approach for expert-guided model building: The example of health literacy. Eval. Program Plann. 2017, 60, 245-253. [CrossRef] [PubMed]

54. Kuhlmann, K.; Beauducel, A.; Predel, G.; Preuß, M.; Preuß, P.; Rudinger, G. Evaluation des Gesundheitsverhaltens Studierender. Diagnostica 2015, 61, 163-171. [CrossRef]

55. World Health Organization. Obesity-Preventing and Managing the Global Epidemic. Report on a WHO Consultation; World Health Organization: Geneva, Switzerland, 2000.

56. Schienkiewitz, A.; Mensink, G.B.M.; Kuhnert, R.; Lange, C. Übergewicht und Adipositas bei Erwachsenen in Deutschland: Fact Sheet. J. Health Monit. 2017, 2, 21-28. [CrossRef]

57. Betz, M.; Cassel, W.; Köhler, U. Schlafgewohnheiten und Gesundheit bei Jugendlichen und jungen Erwachsenen - Auswirkungenen von Schlafdefizit auf Leistungsfähigkeit und Wohlbefinden. Dtsch. med. Wochenschr. 2012, 137. [CrossRef]

58. Robert Koch-Institut. Ergebnisse der Studie "Gesundheit in Deutschland aktuell 2012". Beiträge zur Gesundheitsberichterstattung des Bundes. RKI: Berlin, Germany, 2014.

59. Statistisches Bundesamt (Destatis). Bildung und Kultur: Berufliche Bildung 2018. Available online: https://www.destatis.de/DE/Themen/Gesellschaft-Umwelt/Bildung-Forschung-Kultur/BeruflicheBildung/Publikationen/Downloads-Berufliche-Bildung/berufliche-bildung-2110300187004.pdf?_blob= publicationFile (accessed on 23 February 2020).

60. Clarke, A.M.; Kuosmanen, T.; Barry, M.M. A systematic review of online youth mental health promotion and prevention interventions. J. Youth Adolesc. 2015, 44, 90-113. [CrossRef] [PubMed]

61. Nour, M.; Yeung, S.H.; Partridge, S.; Allman-Farinelli, M. A Narrative Review of Social Media and Game-Based Nutrition Interventions Targeted at Young Adults. J. Acad. Nutr. Diet. 2017, 117, 735-752. [CrossRef] [PubMed]

62. Nölke, L.; Mensing, M.; Krämer, A.; Hornberg, C. Sociodemographic and health-(care-)related characteristics of online health information seekers: A cross-sectional German study. BMC Public Health 2015, 15, 31. [CrossRef] [PubMed]

63. Ashton, L.M.; Hutchesson, M.J.; Rollo, M.E.; Morgan, P.J.; Collins, C.E. A scoping review of risk behaviour interventions in young men. BMC Public Health 2014, 14, 957. [CrossRef] [PubMed]

64. Pagoto, S.L.; Schneider, K.L.; Oleski, J.L.; Luciani, J.M.; Bodenlos, J.S.; Whited, M.C. Male inclusion in randomized controlled trials of lifestyle weight loss interventions. Obesity (Silver Spring) 2012, 20, 1234-1239. [CrossRef] [PubMed]

65. Joseph, R.P.; Durant, N.H.; Benitez, T.J.; Pekmezi, D.W. Internet-Based Physical Activity Interventions. Am. J. Lifestyle Med. 2014, 8, 42-68. [CrossRef]

66. Ashton, L.M.; Morgan, P.J.; Hutchesson, M.J.; Rollo, M.E.; Collins, C.E. Young Men's Preferences for Design and Delivery of Physical Activity and Nutrition Interventions: A Mixed-Methods Study. Am. J. Mens. Health 2017, 11, 1588-1599. [CrossRef]

67. Suri, V.R.; Majid, S.; Chang, Y.-K.; Foo, S. Assessing the influence of health literacy on health information behaviors: A multi-domain skills-based approach. Patient Educ. Couns. 2016, 99, 1038-1045. [CrossRef]

68. Diviani, N.; van den Putte, B.; Giani, S.; van Weert, J.C. Low health literacy and evaluation of online health information: A systematic review of the literature. J. Med. Internet Res. 2015, 17, e112. [CrossRef] 
69. Stellefson, M.; Hanik, B.; Chaney, B.; Chaney, D.; Tennant, B.; Chavarria, E.A. eHealth literacy among college students: A systematic review with implications for eHealth education. J. Med. Internet Res. 2011, 13 , e102. [CrossRef]

70. Cook, T.L.; de Bourdeaudhuij, I.; Maes, L.; Haerens, L.; Grammatikaki, E.; Widhalm, K.; Kwak, L.; Plada, M.; Moreno, L.A.; Zampelas, A.; et al. Moderators of the effectiveness of a web-based tailored intervention promoting physical activity in adolescents: The HELENA Activ-O-Meter. J. Sch. Health 2014, 84, 256-266. [CrossRef]

71. Morton, C.E.; Saleh, S.N.; Smith, S.F.; Hemani, A.; Ameen, A.; Bennie, T.D.; Toro-Troconis, M. Blended learning: How can we optimise undergraduate student engagement? BMC Med. Educ. 2016, 16, 195. [CrossRef]

72. Neil, A.L.; Batterham, P.; Christensen, H.; Bennett, K.; Griffiths, K.M. Predictors of adherence by adolescents to a cognitive behavior therapy website in school and community-based settings. J. Med. Internet Res. 2009, 11, e6. [CrossRef] [PubMed]

73. Nitsch, M.; Adamcik, T.; Kuso, S.; Zeiler, M.; Waldherr, K. Usability and Engagement Evaluation of an Unguided Online Program for Promoting a Healthy Lifestyle and Reducing the Risk for Eating Disorders and Obesity in the School Setting. Nutrients 2019, 11, 713. [CrossRef] [PubMed]

74. de Bourdeaudhuij, I.; Maes, L.; de Henauw, S.; de Vriendt, T.; Moreno, L.A.; Kersting, M.; Sarri, K.; Manios, Y.; Widhalm, K.; Sjöstrom, M.; et al. Evaluation of a computer-tailored physical activity intervention in adolescents in six European countries: The Activ-O-Meter in the HELENA intervention study. J. Adolesc. Health 2010, 46, 458-466. [CrossRef]

75. Schoeppe, S.; Alley, S.; van Lippevelde, W.; Bray, N.A.; Williams, S.L.; Duncan, M.J.; Vandelanotte, C. Efficacy of interventions that use apps to improve diet, physical activity and sedentary behaviour: A systematic review. Int. J. Behav. Nutr. Phys. Act. 2016, 13, 127. [CrossRef] [PubMed]

76. Vandelanotte, C.; Spathonis, K.M.; Eakin, E.G.; Owen, N. Website-delivered physical activity interventions a review of the literature. Am. J. Prev. Med. 2007, 33, 54-64. [CrossRef] [PubMed]

77. MacPherson, M.M.; Merry, K.J.; Locke, S.R.; Jung, M.E. Effects of Mobile Health Prompts on Self-Monitoring and Exercise Behaviors Following a Diabetes Prevention Program: Secondary Analysis From a Randomized Controlled Trial. JMIR Mhealth Uhealth 2019, 7, e12956. [CrossRef] [PubMed]

78. Bidargaddi, N.; Almirall, D.; Murphy, S.; Nahum-Shani, I.; Kovalcik, M.; Pituch, T.; Maaieh, H.; Strecher, V. To Prompt or Not to Prompt? A Microrandomized Trial of Time-Varying Push Notifications to Increase Proximal Engagement With a Mobile Health App. JMIR Mhealth Uhealth 2018, 6, e10123. [CrossRef]

79. Robroek, S.J.W.; Lindeboom, D.E.M.; Burdorf, A. Initial and sustained participation in an internet-delivered long-term worksite health promotion program on physical activity and nutrition. J. Med. Internet Res. 2012, 14, e43. [CrossRef]

80. Fry, J.P.; Neff, R.A. Periodic prompts and reminders in health promotion and health behavior interventions: Systematic review. J. Med. Internet Res. 2009, 11, e16. [CrossRef]

81. Alkhaldi, G.; Hamilton, F.L.; Lau, R.; Webster, R.; Michie, S.; Murray, E. The Effectiveness of Prompts to Promote Engagement With Digital Interventions: A Systematic Review. J. Med. Internet Res. 2016, 18, e6. [CrossRef] [PubMed]

82. Tong, H.L.; Coiera, E.; Laranjo, L. Using a Mobile Social Networking App to Promote Physical Activity: A Qualitative Study of Users' Perspectives. J. Med. Internet Res. 2018, 20, e11439. [CrossRef] [PubMed]

83. Middelweerd, A.; van der Laan, D.M.; van Stralen, M.M.; Mollee, J.S.; Stuij, M.; te Velde, S.J.; Brug, J. What features do Dutch university students prefer in a smartphone application for promotion of physical activity? A qualitative approach. Int. J. Behav. Nutr. Phys. Act. 2015, 12, 31. [CrossRef] [PubMed]

84. Dute, D.J.; Bemelmans, W.J.E.; Breda, J. Using Mobile Apps to Promote a Healthy Lifestyle Among Adolescents and Students: A Review of the Theoretical Basis and Lessons Learned. JMIR Mhealth Uhealth 2016, 4, e39. [CrossRef]

85. Poobalan, A.S.; Aucott, L.S.; Clarke, A.; Smith, W.C.S. Physical activity attitudes, intentions and behaviour among 18-25 year olds: A mixed method study. BMC Public Health 2012, 12, 640. [CrossRef]

86. Giles, E.L.; Brennan, M. Changing the lifestyles of young adults. J. Soc. Mark. 2015, 5, 206-225. [CrossRef] 
87. Berry, E.; Aucott, L.; Poobalan, A. Are young adults appreciating the health promotion messages on diet and exercise? J. Public Health (Berl.) 2018, 26, 687-696. [CrossRef]

88. Horvath, K.J.; Ecklund, A.M.; Hunt, S.L.; Nelson, T.F.; Toomey, T.L. Developing Internet-based health interventions: A guide for public health researchers and practitioners. J. Med. Internet. Res. 2015, 17, e28. [CrossRef]

89. Blandford, A.; Gibbs, J.; Newhouse, N.; Perski, O.; Singh, A.; Murray, E. Seven lessons for interdisciplinary research on interactive digital health interventions. Digit. Health 2018, 4. [CrossRef]

90. Baker, T.B.; Gustafson, D.H.; Shah, D. How can research keep up with eHealth? Ten strategies for increasing the timeliness and usefulness of eHealth research. J. Med. Internet Res. 2014, 16, e36. [CrossRef]

91. Rogers, E.M. Diffusion of Innovations, 5th ed.; Simon\&Schuster: New York, NY, USA, 2003.

92. Couper, M.P.; Alexander, G.L.; Zhang, N.; Little, R.J.A.; Maddy, N.; Nowak, M.A.; McClure, J.B.; Calvi, J.J.; Rolnick, S.J.; Stopponi, M.A.; et al. Engagement and retention: Measuring breadth and depth of participant use of an online intervention. J. Med. Internet. Res. 2010, 12, e52. [CrossRef] [PubMed]

93. Morrison, L.G.; Geraghty, A.W.A.; Lloyd, S.; Goodman, N.; Michaelides, D.T.; Hargood, C.; Weal, M.; Yardley, L. Comparing usage of a web and app stress management intervention: An observational study. Internet Interv. 2018, 12, 74-82. [CrossRef] [PubMed]

94. Short, C.E.; DeSmet, A.; Woods, C.; Williams, S.L.; Maher, C.; Middelweerd, A.; Müller, A.M.; Wark, P.A.; Vandelanotte, C.; Poppe, L.; et al. Measuring Engagement in eHealth and mHealth Behavior Change Interventions: Viewpoint of Methodologies. J. Med. Internet Res. 2018, 20, e292. [CrossRef] [PubMed]

95. Ryan, C.; Bergin, M.; Wells, J.S. Theoretical Perspectives of Adherence to Web-Based Interventions: A Scoping Review. Int. J. Behav. Med. 2018, 25, 17-29. [CrossRef]

96. Miller, S.; Ainsworth, B.; Yardley, L.; Milton, A.; Weal, M.; Smith, P.; Morrison, L. A Framework for Analyzing and Measuring Usage and Engagement Data (AMUsED) in Digital Interventions: Viewpoint. J. Med. Internet Res. 2019, 21, e10966. [CrossRef]

97. Park, S.Y. An Analysis of the Technology Acceptance Model in Understanding University Students' Behavioral Intention to Use e-Learning. J. Edu. Tech. Soc. 2009, 12, 150-162.

98. Yardley, L.; Spring, B.J.; Riper, H.; Morrison, L.G.; Crane, D.H.; Curtis, K.; Merchant, G.C.; Naughton, F.; Blandford, A. Understanding and Promoting Effective Engagement With Digital Behavior Change Interventions. Am. J. Prev. Med. 2016, 51, 833-842. [CrossRef]

99. Sieverink, F.; Kelders, S.M.; van Gemert-Pijnen, J.E. Clarifying the Concept of Adherence to eHealth Technology: Systematic Review on When Usage Becomes Adherence. J. Med. Internet Res. 2017, 19 , e402. [CrossRef]

100. Brouwer, W.; Oenema, A.; Crutzen, R.; de Nooijer, J.; de Vries, N.K.; Brug, J. What makes people decide to visit and use an internet-delivered behavior-change intervention? Health Edu. 2009, 109, 460-473. [CrossRef]

101. Brouwer, W.; Oenema, A.; Crutzen, R.; de Nooijer, J.; de Vries, N.K.; Brug, J. An exploration of factors related to dissemination of and exposure to internet-delivered behavior change interventions aimed at adults: A Delphi study approach. J. Med. Internet. Res. 2008, 10, e10. [CrossRef]

102. Reinwand, D.A.; Crutzen, R.; Elfeddali, I.; Schneider, F.; Schulz, D.N.; Smit, E.S.; Stanczyk, N.E.; Tange, H.; Voncken-Brewster, V.; Walthouwer, M.J.L.; et al. Impact of Educational Level on Study Attrition and Evaluation of Web-Based Computer-Tailored Interventions: Results From Seven Randomized Controlled Trials. J. Med. Internet Res. 2015, 17, e228. [CrossRef]

103. van Poppel, M.N.M.; Chinapaw, M.J.M.; Mokkink, L.B.; van Mechelen, W.; Terwee, C.B. Physical activity questionnaires for adults: A systematic review of measurement properties. Sports Med. 2010, 40, 565-600. [CrossRef] [PubMed]

104. Helmerhorst, H.J.F.; Brage, S.; Warren, J.; Besson, H.; Ekelund, U. A systematic review of reliability and objective criterion-related validity of physical activity questionnaires. Int. J. Behav. Nutr. Phys. Act. 2012, 9, 103. [CrossRef] [PubMed]

105. Altin, S.V.; Finke, I.; Kautz-Freimuth, S.; Stock, S. The evolution of health literacy assessment tools: A systematic review. BMC Public Health 2014, 14, 1207. [CrossRef] [PubMed]

106. Haun, J.N.; Valerio, M.A.; McCormack, L.A.; Sørensen, K.; Paasche-Orlow, M.K. Health literacy measurement: An inventory and descriptive summary of 51 instruments. J. Health Commun. 2014, 19 (Suppl. 2), 302-333. [CrossRef] 
107. Morrison, C.; Doherty, G. Analyzing engagement in a web-based intervention platform through visualizing log-data. J. Med. Internet Res. 2014, 16, e252. [CrossRef] [PubMed]

108. Arden-Close, E.J.; Smith, E.; Bradbury, K.; Morrison, L.; Dennison, L.; Michaelides, D.; Yardley, L. A Visualization Tool to Analyse Usage of Web-Based Interventions: The Example of Positive Online Weight Reduction (POWeR). JMIR Hum. Factors 2015, 2, e8. [CrossRef]

(C) 2020 by the authors. Licensee MDPI, Basel, Switzerland. This article is an open access article distributed under the terms and conditions of the Creative Commons Attribution (CC BY) license (http://creativecommons.org/licenses/by/4.0/). 